\title{
Enhancement of Electrocatalytic Activity upon the Addition of Single Wall Carbon Nanotube to the Redox-hydrogel-based Glucose Sensor
}

\author{
Suk-Joon $\mathrm{Kim}^{1}$, Yuzhong Quan ${ }^{2}$, Eunhyeon $\mathrm{Ha}^{1}$, and Woonsup Shin ${ }^{1,2 *}$ \\ ${ }^{1}$ Department of Chemistry, Sogang University, Seoul 121-742, Korea \\ ${ }^{2}$ Department of Biomedical Engineering, Sogang University, Seoul 121-742, Korea
}

\begin{abstract}
In electrochemical glucose sensing, the enhancement of the sensitivity and the response time is essential in developing stable and reliable sensors, especially for continuous glucose monitoring. We developed a method to increase the sensitivity and to shorten the response time for the sensing upon the appropriate addition of single wall carbon nanotube onto the osmium polymer-based hydrogel electrode. Also, the background stabilization is dramatically enhanced.
\end{abstract}

Keywords : Continuous Glucose Monitoring System, Enzymatic Glucose Sensor, Single Wall Carbon Nanotube

Received : 8 June 2020, Accepted : 29 July 2020

\section{Introduction}

For diabetes, the monitoring of a blood glucose level is the most important to control the disease. The electrochemical sensing is the most versatile method because of its advantage in the point-of-care test [1]. Both glucose oxidase (GOx) or glucose dehydrogenase $(\mathrm{GDH})$ is employed to make a selective and sensitive layer for detecting glucose from the complex mixture of blood or interstitial fluid [2].

Currently, both a single-use disposable strip sensor to measure the glucose level in the finger capillary blood and a continuous glucose sensor to monitor the glucose level in the interstitial fluid of the subcutaneous region are in use [3]. For continuous glucose monitoring (CGM), the increase of the sensitivity is essential because of the presence of a thick biocompatible outer layer to measure the glucose concentration in the interstitial fluid under the subcutaneous region for a long time [4]. For the enhancement of the electron transfer rate in the hydrogel containing GOx or GDH, the redox polymers containing ferrocene

*E-mail address: shinws@sogang.ac.kr

DOI: https://doi.org/10.33961/jecst.2020.01039

This is an open-access article distributed under the terms of the Creative Commons Attribution Non-Commercial License (http://creativecommons.org/licenses/by-nc/4.0) Attribution Non-Commercial License (http://creativecommons.org/licenses/by-nc/4.0)
which permits unrestricted non-commercial use, distribution, and reproduction in any which permits unrestricted non-commercial use, distrib
medium, provided the original work is properly cited.
[5], ferricyanide [6], ruthenium complexes [7], or osmium complexes [8-12] have been utilized. Besides, active carbons [13], graphene [14], carbon nanotubes [15], and metal nanowires [16] were added as conductors to the mixture of the sensing layer to improve the conductivity and the electron transfer efficiency [17-24].

In this paper, we report the first observation of the dramatic increase in the sensitivity of 10 times and the rapid response time in a few seconds upon the addition of single-wall carbon nanotube (SWCNT) to the sensing layer made of osmium polymer, linkers, and GDH.

\section{Experimental}

\subsection{Reagents, Materials, and Equipments}

Glucose dehydrogenase (FAD-GDH), D-glucose, poly(ethylene glycol)diglycidyl ether (PEGDGE, MW 500), 2,6-dichloroindophenol (DCIP), 5-methylphenazinium methyl sulfate (PMS) are purchased from Sigma Aldrich. Potassium phosphate, sodium chloride, potassium chloride, disodium phosphate, and monopotassium phosphate are from Alfa Aesar. Single wall carbon nanotube (SWCNT) used is Tuball $^{\mathrm{TM}}$ from Ocsial (below $2 \mathrm{~nm}$ diameter, $>1$ um length). Polyvinylimidazole-osmium(bipyridine) ${ }_{2}$ 
chloride [PVI-Os(bpy $)_{2} \mathrm{Cl}$ ] is synthesized based on the literature [25]. Screen printed carbon electrode (SPCE) is purchased from Zensor (SE100, $5 \mathrm{~mm}$ diameter), Taiwan. Deionized water is from Purelab option Q. Ultrasonication for the dispersion of SWCNTs is performed by VC505 from Sonics Co. Scanning electron microscopic (SEM) images are obtained by SNE-4500M from SEC Co., Ltd. Electrochemical measurements are done by CHI 1230A potentiostat system. The spectrophotometric measurements of the activity assay are performed by Agilent 8453 spectrophotometer.

\subsection{Preparation of Electrode}

\subsubsection{Preparation of SWCNT dispersion}

SWCNT is dispersed by Triton X-100 in aqueous solution by ultrasonication for 20 minutes at 3 seconds pulse and 3 seconds rest. The concentration is $0.5 \mathrm{mg} /$ $\mathrm{mL}$ for SWCNT and $5 \mathrm{mg} / \mathrm{mL}$ for Triton X-100.

\subsubsection{GDH/Os-polymer/PEGDGE electrode}

Stock solutions of glucose dehydrogenase (GDH), Os-polymer (PVI-Os(bpy $\left.)_{2} \mathrm{Cl}\right)$, and PEGDGE are prepared to be 40,5 , and $10 \mathrm{mg} / \mathrm{mL}$, respectively. Then, those are mixed in appropriate volumes to be a weight ratio of 42:46:5.8. The concentration of the final total solution is $4.5 \mathrm{mg} / \mathrm{mL}$, and $5 \mathrm{uL}$ of the mixed solution is drop-coated onto an air plasmatreated SPCE. The electrode is used after drying for one day at ambient conditions.

2.2.3 GDH/Os-polymer/PEGDGE/SWCNT electrode In the case of the SWCNT-containing glucose sensor, $0.5 \mathrm{mg} / \mathrm{mL}$ SWCNT solution containing $5 \mathrm{mg} / \mathrm{mL}$ of Triton X-100, is additionally added. Then, the weight ratio of GDH, Os-polymer, PEGDGE, SWCNT is 42:46:5.8:5.4. For the preparation of the sensing layer, similarly, $5 \mathrm{uL}$ mixed solution of $4.5 \mathrm{mg} / \mathrm{mL}$ final solution is drop-coated onto an air plasma-treated SPCE and dried for one day before use.

\subsection{Electrochemical Measurements}

For CV (cyclic voltammetry) and amperometric measurements, SPCE working, Pt wire counter, and $\mathrm{Ag} / \mathrm{AgCl}$ reference electrodes are used. Amperometric glucose sensing is measured by adding $1 \mathrm{M}$ glucose solution dropwise to the stirred PBS (phosphate buffer saline, $\mathrm{pH} 7.4$ ) solution.
2.4 Glucose dehydrogenase (GDH) activity assay

The activity assay is modified from the literature [26], and the assay solution is made by adding $2.0 \mathrm{~mL}$ of $0.1 \mathrm{M}$ phosphate (pH 7.4), $300 \mathrm{uL}$ of $2 \mathrm{M}$ D-glucose, $75 \mathrm{uL}$ of $1.8 \mathrm{mM}$ DCIP, and $50 \mathrm{uL}$ of $30 \mathrm{mM}$ PMS solutions. The spectrophotometric measurement is started upon adding $5 \mathrm{uL}$ of $0.05 \sim 0.2 \mathrm{mg} /$ $\mathrm{mL}$ GDH solution into the assay solution at $600 \mathrm{~nm}$.

\section{Results and Discussion}

\subsection{Activity assay}

The activity of GDH is measured by the absorbance decrease at $600 \mathrm{~nm}$, where the oxidized DCIP changes to the reduced form, upon accepting the electron through PMS from the reduced GDH. The following is the one example to measure the activity of the freshly-prepared $0.1 \mathrm{mg} / \mathrm{mL}$ GDH solution. It shows the specific activity of 141 units/mg (Fig. 1).

\subsection{SEM analysis of the sensing layer}

SEM analysis of the bare-SPCE and the sensing layer coated SPCE is shown in Fig. 2.

The amount of the sensing layer coated is $5 \mathrm{uL}$ of $4.5 \mathrm{mg} / \mathrm{mL}$ cocktail solution. Then, the thickness of the sensing layer can be estimated to $2 \mathrm{um}$. Because the surface of the SPCE is quite rough, as shown in the SEM images, it was difficult to distinguish the bare SPCE and the coated-SPCE.

\subsection{Electrochemical Properties of the GDH/Os-} polymer/PEGDGE/SWCNT electrode

The electrochemical properties of the GDH/Ospolymer/PEGDGE/SWCNT electrode are compared

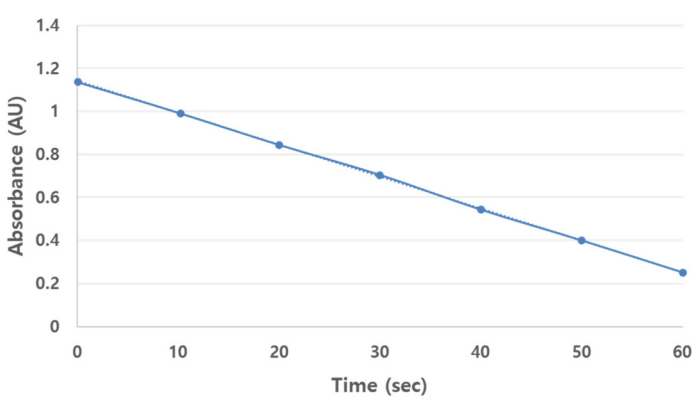

Fig. 1. An example of the activity assay of GDH upon measuring the decrease of the absorbance at $600 \mathrm{~nm}$, where DCIP turns to the reduced form upon accepting the electron originated from glucose. 
a)

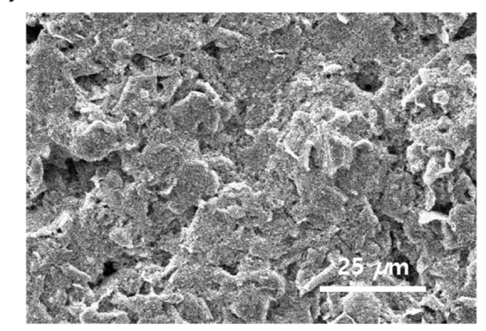

c)

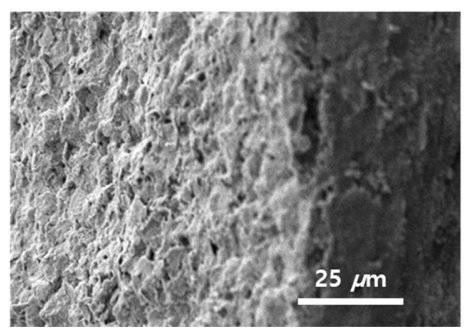

b)

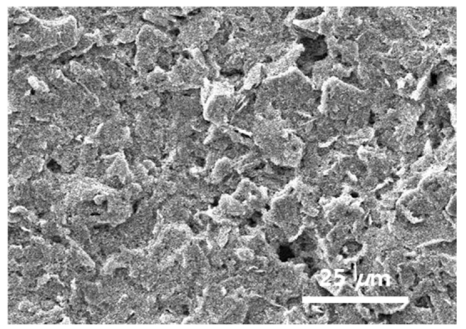

d)

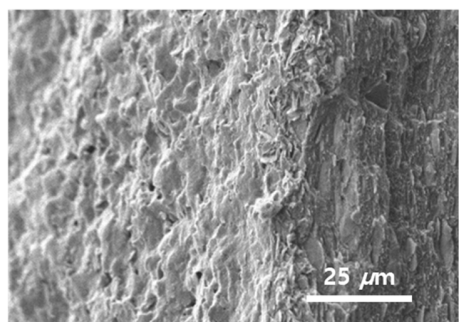

Fig. 2. SEM image of SPCE surface(a, c) and glucose sensing layer(b, d)

a)

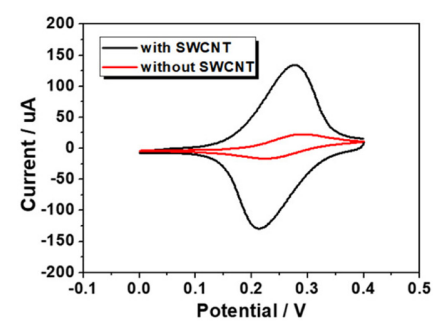

b)

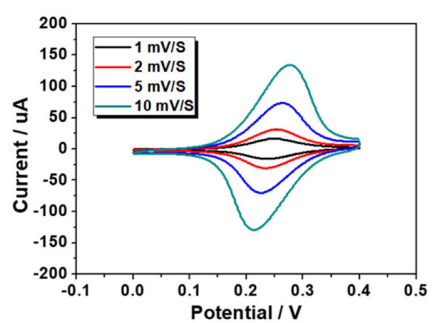

c)

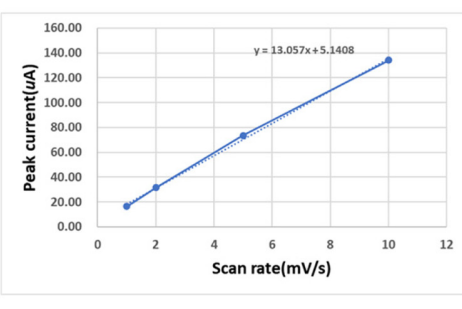

Fig. 3. Cyclic voltammograms of the sensors at $10 \mathrm{mV} / \mathrm{s}$, with and without SWCNT (a), scan rate dependent responses from 1 to $10 \mathrm{mV} / \mathrm{s}$ for the sensor with SWCNT (b), and plot of peak current dependent on scan rate (c)

with GDH/Os-polymer/PEGDGE electrode and scan rate dependent responses for the sensor with SWCNT are recorded (Fig. 3).

The electrode containing SWCNT exhibited seven times higher current than that of the electrode without SWCNT, while the redox potential is not much changed (Fig.3a). The current response to the scan rate is linear up to $10 \mathrm{mV} / \mathrm{sec}$ (Fig.3b), and it shows the surface-confined electron transfer reaction through the polymer composite. While the electrode without SWCNT does not.

\subsection{Amperometric sensing of glucose}

The amperometric response to glucose of the GDH/Os-polymer/PEGDGE/SWCNT electrode is compared to the electrode without SWCNT. It is measured at $+0.35 \mathrm{~V}$ vs. $\mathrm{Ag} / \mathrm{AgCl}$ upon changing the glucose concentration from 0 to $5 \mathrm{mM}$ by the addition of an appropriate volume of $1 \mathrm{M}$ glucose solution into $10 \mathrm{~mL}$ PBS solution while stirring. The glucose response of the electrode containing SWCNT is more than 20 times larger than that of the electrode without SWCNT, i.e., 17.2 uA/mM for the SWCNT-containing electrode and $0.79 \mathrm{uA} / \mathrm{mM}$ for the electrode without SWCNT.

The response time of the electrode with SWCNT is much faster than that of the electrode without SWCNT (Fig. 5). The time to reach $95 \%$ of steadystate current $\left(\mathrm{t}_{95 \%}\right)$ for SWCNT containing glucose sensor is 6 secs, while for the glucose sensor without $\mathrm{SWCNT}$, it is $245 \mathrm{secs}$. The response time is $163 \mathrm{uA} /$ min for SWCNT-containing one and $0.18 \mathrm{uA} / \mathrm{min}$ for 


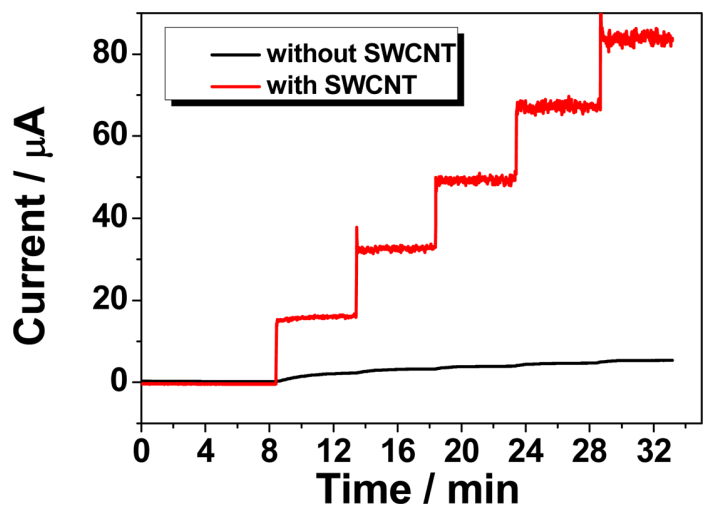

Fig. 4. Amperometric response at $+0.35 \mathrm{~V}$ vs. $\mathrm{Ag} / \mathrm{AgCl}$ of the sensors with and without SWCNT in PBS solution while changing glucose concentration from 0 to $5 \mathrm{mM}$ at $1 \mathrm{mM}$ increment.

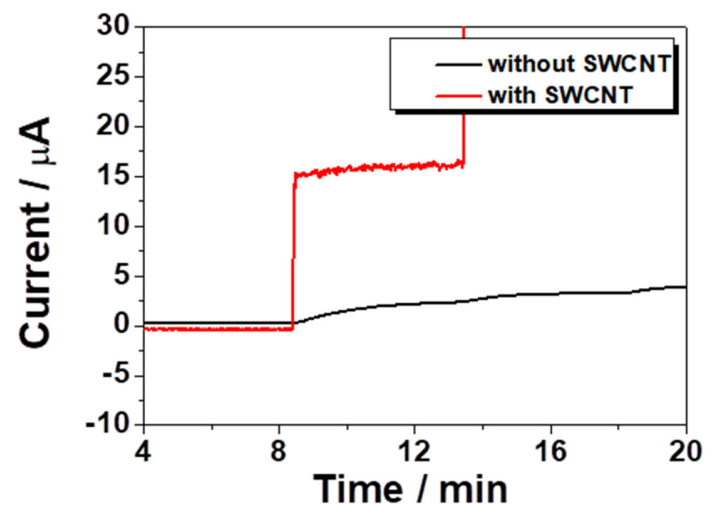

Fig. 5. Comparison of the response time with and without SWCNT from the change of 0 to $1 \mathrm{mM}$ glucose in PBS solution.

the one without SWCNT.

The baseline stabilization is also much faster for the SWCNT containing electrode than the electrode without SWCNT, i.e., the electrode containing SWCNT is stabilized almost instantly but, in case of the electrode without SWCNT, the stabilization time is over several minutes (Fig. 6).

In summary, for the electrode containing the SWCNT, the current response becomes 10 times higher, the response time to the change of the glucose concentration is very fast in a few seconds, and the stabilization of the background is almost instant.

The high sensitivity and the rapid responses of the SWCNT containing electrode can be explained by

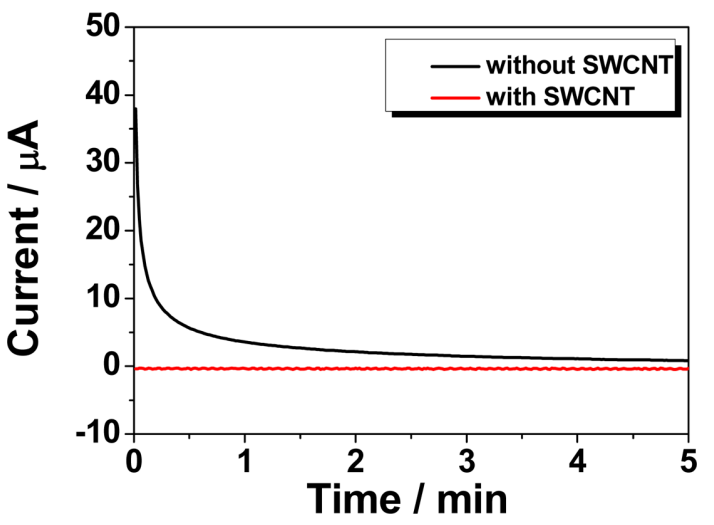

Fig. 6. Comparison of the stabilization time of the sensor with and without SWCNT in PBS solution. a)

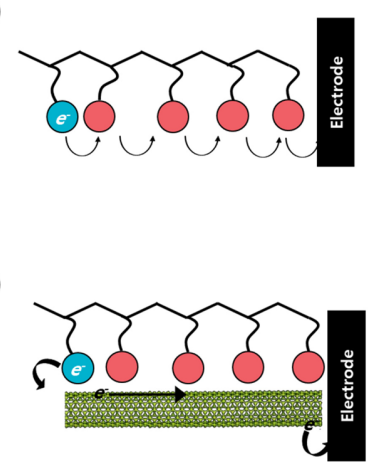

b)

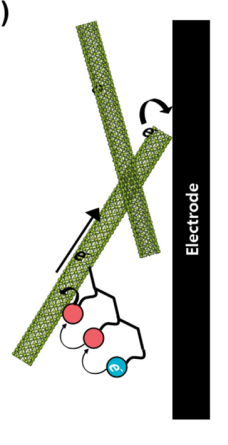

Fig. 7. The mechanism of electron transfer through (a) the collision of osmium redox centers, (b) the shorten the collisional distance by SWCNT, and (c) the direct conduction through SWCNT

the fast and efficient transport of charges along the SWCNT-driven structure in the polymer composite. The osmium-based redox polymers are known to have an efficient electron transfer by the collisional diffusion of the redox centers in the hydrogel (Fig. 7(a)) [27]. If SWCNTs are added, the collisional transport pathway can be shortened by both the network of SWCNT (Fig. 7(b)) and the direct electron transfer route from the redox center to the SWCNT (Fig. 7(c)).

For the CV measurements (Fig. 3), the linear response of the peak current to the scan rate for the SWCNT containing electrode confirms the shortening of the diffusional distance shown in the above explanation. 
Some reports are using a single-wall carbon nanotube similar to this study $[28,29]$; however, the electron transport capability of SWCNT is not fully utilized because the coating was layer-by-layer of the SWCNT first and the polymer/enzyme layer second. In the current study, SWCNT was well-mixed with the polymer/enzyme and formed as one coating on the surface of the electrode. Consequently, the interactions among the redox centers, the conductors, and the enzymes are maximized. The sensing film fabricated in the present method shows the high current response, the fast response time, and the rapid stabilization of the background, which can be utilized for the sensing layer of continuous glucose monitoring.

\section{Conclusions}

Upon the appropriate addition of SWCNT to the osmium polymer-based hydrogel containing GDH, the charge transfer rate in the sensing layer is maximized to enhance the response current, response time. The electrode performance is enough to be utilized for building a continuous glucose monitoring sensor.

\section{Acknowlegments}

This research was supported by the Next-generation Medical Device Development Program for Newly-Created Market of the National Research Foundation (NRF) funded by the Korean government, MSIP (No. 2015M3D5A1065759).

\section{References}

[1] E. H. Yoo, and S. Y. Lee, Sensors, 2010, 10, 4558-4576.

[2] S. Ferri, K. Kojima, K. Sode, J. Diabetes Sci. Technol., 2011, 5, 1068-1076.

[3] L. Heinemann, J. Diabetes Sci. Technol., 2018, 12, 873879.

[4] W. J. Sung, k. Na, Y. H. Bae, Sensors Actuators, B Chem., 2004, 99, 393-398.

[5] Z. Jiang, Y. Shangguan and Q. Zheng, Polymers., 2019, 15, 53-63.

[6] F. Arslan, U. Beskan, ArtifCells Nanomed Biotechnol, 2014, 42, 284-288.
[7] Deng, H., Teo, A. K. L. \& Gao, Z. Sensors Actuators, $B$ Chem., 2014, 191, 522-528.

[8] F. Mao, N. Mano and A. Heller, J. Am. Chem. Soc., 2003, 125, 4951-4957.

[9] A. P. Doherty and J. G. Vos, Anal. Chim. Acta., 1997, 344, 159-166.

[10] Calabrese Barton, S.; Kim, H.-H.; Binyamin, G.; Zhang, Y.; Heller, A. J. Phys. Chem. B, 2001, 105, 1191711921.

[11] Kim, H. H.; Mano, N.; Zhang, X. C.; Heller, A. J. Electrochem. Soc., 2003, 150, A209-A213.

[12] Mano, N.; Mao, F.; Heller, A. J. Am. Chem. Soc., 2002, 124, 12962.

[13] Y. Koskun, A. Şavk, B. Şen and F. Şen, Anal. Chim. Acta., 2018, 66, 37-43.

[14] M. Zhang, C. Liao, C. H. Mak, P. You, C. L. Mak, F. Yan, Sci. Rep., 2015, 5, 1-6.

[15] R. Monošík, M. Stred'anský, K. Lušpai, P. Magdolen and E. Šturdík, Enzyme Microb. Technol., 2012, 50, 227232.

[16] J. Tang, Y. Wnag, J. Li, P. Da, J. Geng, G. Zheng, J. Mater. Chem. A, 2014, 2, 6153-6157.

[17] A. I. Gopalan, N. Muthuchamy, S. Komathi, K. P. Lee, Biosens. Bioelectron., 2016, 84, 53-63.

[18] Q. Gao, Y. Guo, J. Liu, X. Yuan, H. Qi, C. Zhang, Bioelectrochemistry, 2011, 81, 109-113.

[19] L. C. Jiang, and W. De. Zhang, Biosens. Bioelectron., 2010, 25, 1402-1407.

[20] J. Luo, S. Jiang, H. Zhang, J. Jiang, X. Liu, Anal. Chim. Acta, 2012, 709, 47-53.

[21] Y. Degani and A. Heller, J. Am. Chem. Soc., 1989, 111, 2357-2358.

[22] S. H. Jung, Y. K. Lee and Y. K. Son, J. Electrochem. Sci. Technol. 2011, 2, 124-129.

[23] H. Jo, H. Piao and Y. Son, J. Electrochem. Sci. Technol. 2013, 4, 41-45.

[24] Q. B. Bui, D. M. Nguyen, T. M. L. Nguyen, L. K. Kwac, H. G. Kim, S. C. Ko and H. Jeong $J$. Electrochem. Sci. Technol. 2018, 9, 229-237.

[25] T. J. Ohara, R. Rajagopalan and A. Heller, Anal. Chem., 1993, 65, 3512-3517.

[26] Y. Yamashita, S. Ferri, M. L. Huynh, H. Shimizu, H. Yamaoka, Enzyme Microb. Technol., 2013, 52, 123-128.

[27] A. Aoki, and A. Heller, J. Phys. Chem., 1993, 97, 11014-11019.

[28] J. Chen, T. O. Tran, M. T. Ray, D. B. Brunski, J. C. Keay, D. Hickey, M. B. Johnson, D. T. Glatzhofer and D. W. Schmidtke, Langmuir, 2013, 29 10586-10595.

[29] P. P. Joshi, S. A. Merchant, Y. Wang and D. W. Schmidtke, Anal. Chem., 2005, 77, 3183-3188. 